\title{
Suggestions for Supporting a Weight Management Policy at Grocery Stores
}

\author{
Anna-Maria Saarela \\ Savonia University of Applied Sciences, Kuopio FI-70201, Finland
}

\begin{abstract}
Weight management is affected by food choice. It is important to show how challenging an environment a grocery store is from a weight management perspective. The subjects were recruited by delivering 1,000 questionnaires in November-December 2009 at the K-Citymarket Kolmisoppi, Kuopio, Finland. The subjects $(n=36$, age 18-65) were recruited to represent consumers of varied experience in weight management. The subjects' shopping behavior was studied using verbal analysis protocol combined with wireless audio-visual observation, questionnaires and interviews in the K-Citymarket in April-May 2010. For two consecutive tasks, the subjects were given a shopping list of 11 food categories. During the first task, they were asked to select a product they usually buy and during the second task, a product they would use for weight management. The subjects made their decisions routinely as there were none stimuli available at a supermarket in relation to weight management choices apart from versatile, abundant and small-sized labels all over food packages. The subjects had challenges while choosing food, such as the time taken (maximum 225 s) to find a suitable product among all the options of a wide product category, for example, 459 ready meals per product category with the energy variation from 30 to $330 \mathrm{kcal} / 100 \mathrm{~g}$, and understanding all package labels properly, such as the GDA-label in relation to the nutrition content table. The subjects had practical suggestions, such as colored labels in shelves, how consumer-oriented marketing communication and services should be developed and provided by retailers cooperatively with health-care actors to promote consumers' awareness of food choices from the weight management perspective in groceries. For a consumer, it is important to be able to easily find and compare suitable products from a weight management point of view. Successful consumer marketing will achieve desirable results for manufacturers, retailers and consumers as well as benefit the society's welfare in the long run.
\end{abstract}

Key words: Nutrition, marketing, consumer behavior, grocery store.

\section{Introduction}

Weight management is affected by food choice [1]. Simultaneous needs of consumers determine food selection process [2, 3]. It is important to show in practice how challenging a food selection environment a grocery store is to consumers from a weight management perspective [4-8].

Retailers can design versatile, desirable and attractive product assortments and services for consumers. Therefore, actors in retail sector have an enormous power to influence on product assortments and food product development of food industry [9, 10]. Groceries worldwide present the enormous variety of products and the variation of packaging and labelling.

Corresponding author: Anna-Maria Saarela, Dr., Ph.D., M.Sc., research fields: nutrition, food and consumer behavior.
Versatile and desirable assortments should be designed based on consumer needs [9-12].

Consumers will require guidance and services supported by retailers [4, 7, 13]. Enormous and versatile product assortments at groceries possess several challenges to consumer's daily life $[4,7,14$, 15]. For a consumer, it is not an easy task to find and select easily healthier products among all products available as the time is often limited for shopping [4-7, 16]. In addition, variations of energy profiles in relation to one product category possess challenges for product selection [4, 7, 17-20]. Therefore, it is important to point out in practice how environments of grocery stores could support consumers' food choices from the weight management perspective. The main aim of this paper is to summarize key findings and aspects related to the title and five publications 
separately made by the author of this manuscript; i.e., it is a thesis, not an original research [4-8].

\section{Materials and Methods}

The overall study design in a real-life setting, the think aloud combined to wireless audio-visual observation are described in more detail by all the previously published papers by Saarela et al. [4-8]. As a summary of the whole field experiment, the study subjects were recruited by delivering 1,000 questionnaires in Nov-Dec at the K-Citymarket Kolmisoppi, Kuopio. The subjects $(\mathrm{n}=36$, age 18-65) were recruited to represent consumers of varied experience in weight management during their lifespan.

The subjects' shopping behavior was studied using verbal analysis protocol combined with wireless audio-visual observation, questionnaires and interviews in the K-Citymarket in Apr-May 2010. For two consecutive shopping tasks, the study subjects were given a shopping list of 11 food categories. During the first task, they were asked to select a product they usually buy and during the second task, a product they would use for weight management. The level of nutritional knowledge of the study subjects was also assessed and related to the choices made.

\section{Results and Discussion}

In the figure 1 , there is a summary of all key findings related to previously published results [4-8]. For example, according to the observations and the verbalizations collected in a real life-setting, the subjects made their shopping decisions routinely during the typical selection task. Also, there were none stimuli available at a supermarket in relation to choices from the weight management perspective apart from versatile, abundant and small-sized labels all over food packages. Usually, consumers make their product selections quickly without considering any other options [8, 21-23]. Information overload and confusing package can labels lead consumers to select product routinely $[7,8,23-25]$. The familiar design of the product helps consumers to find the familiar product $[5,8,23,26]$.

During the second weight management task, the subjects had several challenges while choosing food, such as the time taken (maximum $225 \mathrm{sec}$ ) to find a suitable product among all the options of a wide product category, for example, 459 ready meals per product category with the energy variation from 30 to $330 \mathrm{kcal} / 100 \mathrm{~g}$, and understanding all package labels properly, such as the GDA-label (Guideline Daily Amount) in relation to the nutrition content table. For successful weight management, it is essential to have the ability to find the low-energy products among high-energy ones [4, 16, 27].

Generally, consumers have pointed out package labels to be complicated [4, 7, 20, 28-30]. However, consumers agree package labels to be useful $[4,7,31]$. Labels must be simple using bigger letters $[4,7,16$, 32]. Consumers also require simple product layouts [ 4 , 33] with specific shelf labelling arrangements $[4,28$, $32,33]$ as well as appreciate health-oriented services provided by retailers $[4,13,34]$.

According to the key findings and comments by the study subjects [4-8], the needs of consumers who are actively managing their weight should be better taken into consideration in grocery stores. The subjects had several practical suggestions, such as colored labels in shelves, how consumer-oriented marketing communication and services should be developed and provided by retailers cooperatively with health-care actors to promote consumers' awareness of food choices from the weight management perspective in grocery stores [20, 35-38]. In the figure 2, there is a summary of suggestions how to support weight management at grocery stores.

For a consumer, it is important to be able to easily find, identify and compare suitable products from a weight management point of view [4-7, 16, 27]. Retailers could also take into consideration to utilize more efficiently possible new services and technologies to support consumer's product selection from the weight 

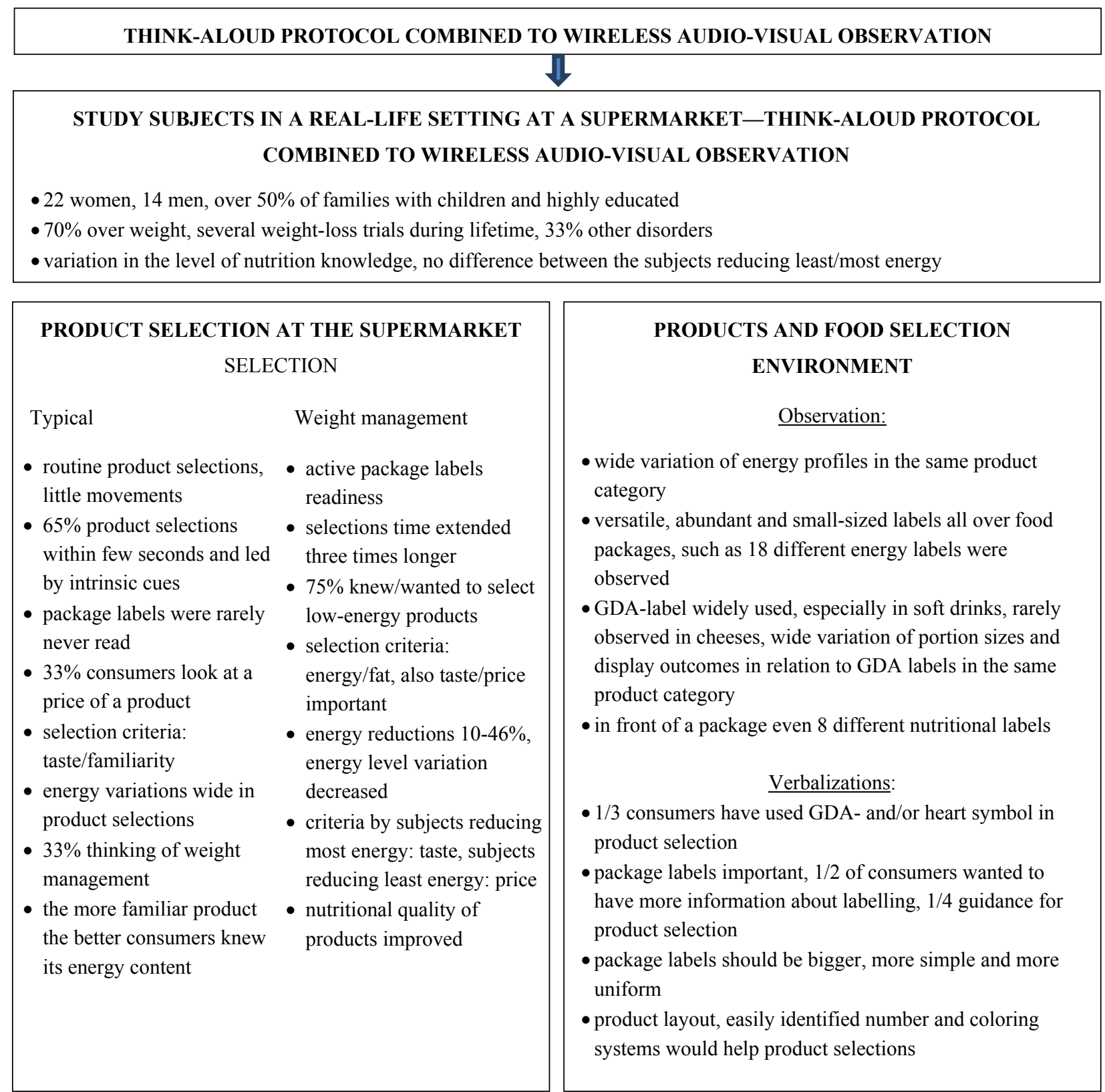

\section{PRODUCTS AND FOOD SELECTION ENVIRONMENT}

\section{Observation:}

- wide variation of energy profiles in the same product category

- versatile, abundant and small-sized labels all over food packages, such as 18 different energy labels were observed

- GDA-label widely used, especially in soft drinks, rarely observed in cheeses, wide variation of portion sizes and display outcomes in relation to GDA labels in the same product category

- in front of a package even 8 different nutritional labels

\section{Verbalizations:}

- 1/3 consumers have used GDA- and/or heart symbol in product selection

- package labels important, $1 / 2$ of consumers wanted to have more information about labelling, $1 / 4$ guidance for product selection

- package labels should be bigger, more simple and more uniform

- product layout, easily identified number and coloring systems would help product selections

Fig. 1 A summary of all previous results published [4-8]. 


\section{CONSUMERS AND FOOD CHOICES AT GROCERY STORES}

How to identify the needs of consumers?

Consumers with different kind of orientations, knowledge and skills in relation to healthy food choices need support and guidance whilst often routinely and quickly selecting food among enormous selection of products available

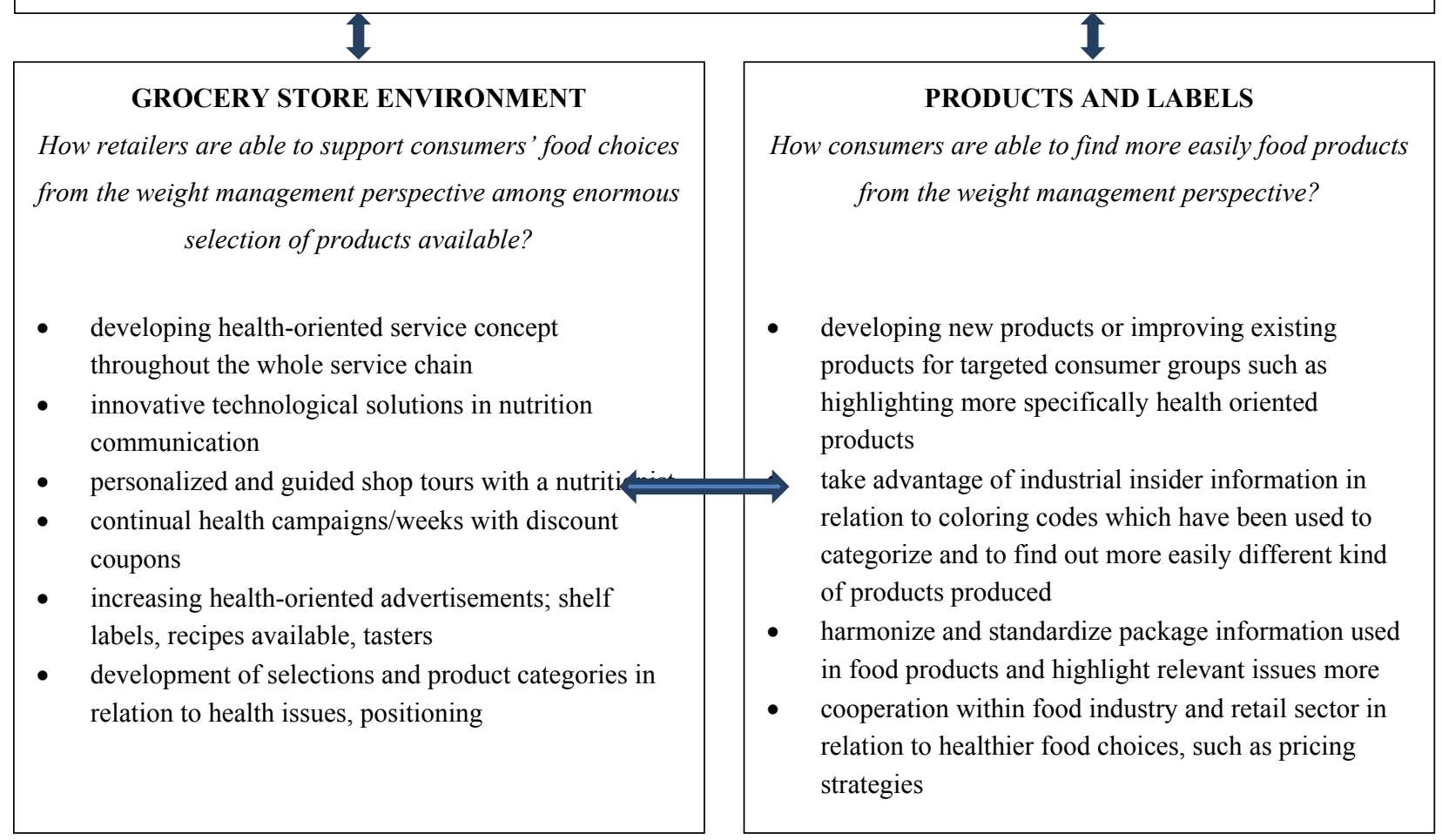

Fig. 2 Summary of practical suggestions how to improve food choices from the weight management perspective at grocery stores.

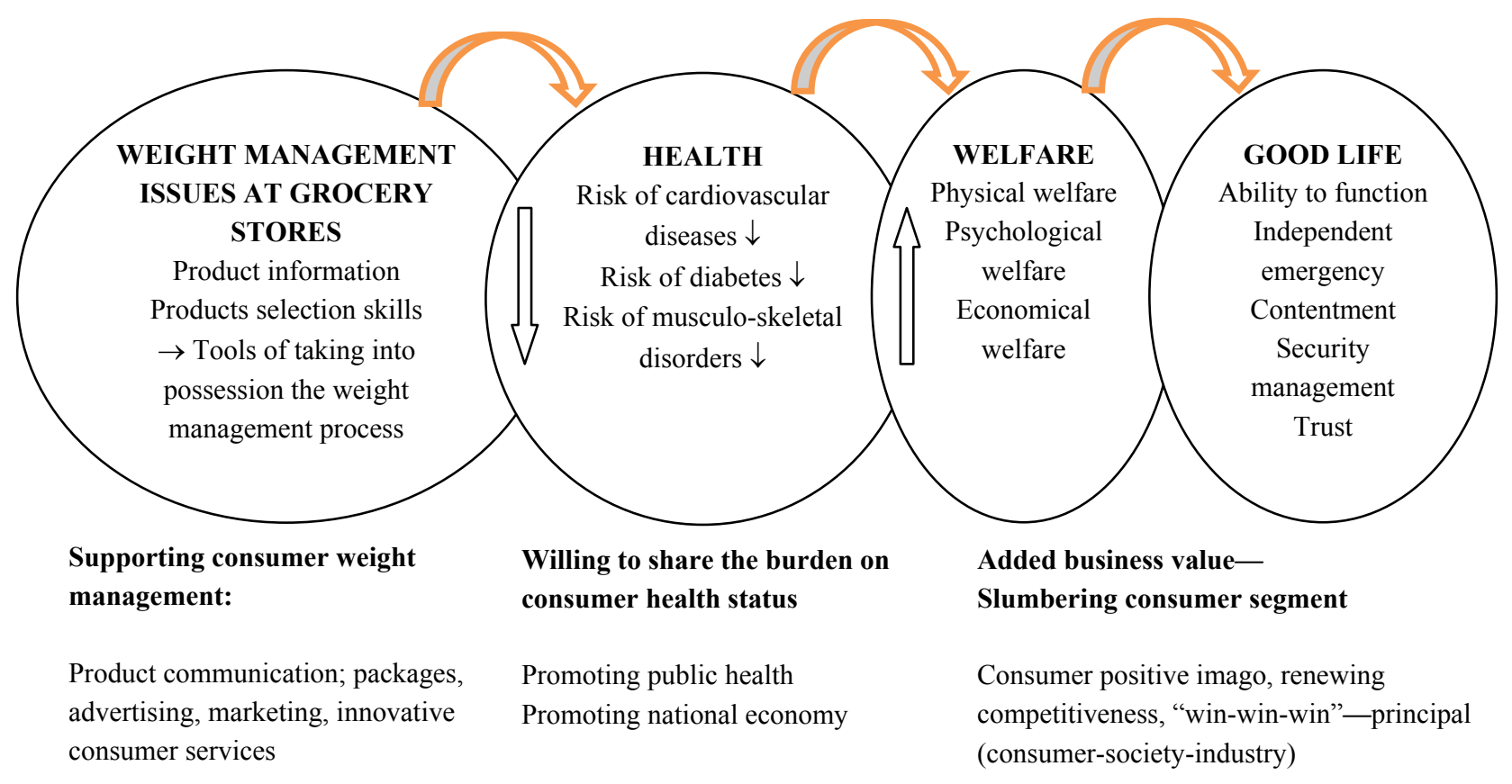

Fig. 3 Weight management strategy for supporting the welfare of individuals, public health and food business. 
management perspective in real-life environments, such as mobile phone applications with personalized assistants, interactive discussion tools, personalized face-to-face counselling at supermarkets, individual recipe services, navigation applications to scan product information in shopping trolleys [4, 9, 19, 39-41]. Successful consumer marketing will achieve desirable results for manufacturers, retailers and consumers as well as benefit the welfare of society's welfare in the long run (Fig. 3) [4, 7, 42].

\section{Acknowledgment}

The thesis was a part of a multidisciplinary project "Consumers on the weight management market" (2009-2011) that analyzed daily choices and experiences of food products related to weight management, and aimed to identify factors that increased individuals' motivation to change their behavior. The project was carried out cooperatively by six universities and research institutes in Finland and was funded by the Finnish Funding Agency for Technology and Innovation, universities and research institutes as well as eight Finnish food companies.

The authors wish to acknowledge Ms. Tammela M.Sc. for recruiting the study subjects, Ms. Meriläinen and Ms. Perttula for their assistance with data collection, and Ms. Rajapolvi for her assistance with the verbal analysis transcription. We are also grateful to the retailer, Mr. Kostilainen, who made it possible to collect data at the supermarket, and the consumers who participated in this study.

\section{References}

[1] Ello-Martin, J. A., Ledikwe, J. H., and Rolls, B. J. 2005. "The Influence of Food Portion Size and Energy Density on Energy Intake: Implications for Weight Management." American Journal of Clinical Nutrition 82: 236-41.

[2] Frewer, L., Risvik, E., and Schifferstein, H. 2010. Food, People and Society. A European Perspective of Concumers' Food Choices. Springer-Verlag Berlin Heidelberg.

[3] Shepherd, R., and Raats, M. 2006. The Psychology of Food Choice. Wallingford: CABI, cop.
[4] Saarela, A. M. 2013. Grocery Store as an Environment for Consumer Food Choices from the Weight Management Perspective, Publications of the University of Eastern Finland, Dissertations in Health Sciences 187.

[5] Saarela, A. M. 2013. Change of Behavior when Selecting Food Products in a Supermarket Environment after Reminding Consumers about Weight Management. Public Health Nutrition doi: 10.1017/S136898001300044X.

[6] Saarela, A. M., Lapveteläinen, A., Mykkänen, H., Kantanen, T., and Rissanen, R. 2013. "Real-Life Setting in Data Collection: the Role of Nutrition Knowledge whilst Selecting Food Products for Weight Management Purposes in a Supermarket Environment." Appetite 71 (1): 196-208, doi: 10.1016/j.appet.2013.08.014.

[7] Saarela, A. M., Keinänen, A. R., and Rissanen, R. 2012. "Energy Profiles and Nutrition Information in Food Product Categories Selected in Finnish Grocery Stores, Considered from a Weight Management Perspective." Journal of Research for Consumers 21: 1-17.

[8] Saarela, A. M., Kantanen, T., Lapveteläinen, A., Mykkänen, H., and Karppinen, H., et al. 2013. "Combining Verbal Analysis Protocol and Wireless Audio-Visual Observation to Examine Consumers' Supermarket Shopping Behavior." International Journal of Consumer Studies doi: 10.1111/ijcs. 12022.

[9] Krafft, M., and Mantrala, M. K. 2010. "Retailing in the 21st Century-Current and Future Trends." Berlin Heiderberg: Springer.

[10] Dawson, J. 2013. "Retailer Activity in Shaping Food Choice." Food Quality and Preference 28: 339-47.

[11] Briesch, R. A., Chintagunta, P. K., and Fox, E. J. 2009. "How does Assortment Affect Grocery Store Choice?" Journal of Marketing Research 46: 176-89.

[12] Morgan, N. A., Kaleka, A., and Gooner, R. A. 2007. "Focal Supplier Opportunism in Supermarket Retailer Category Management." Journal of Operations Management 25: 512-27.

[13] Närhinen, M. 2000. "Healthier Food Choices in Supermarkets." Publications of the University of Kuopio.

[14] Nestle, M. 2007. "Food Politics: How the Food Industry Influences Nutrition and Health." University of Berkley Publications. 2. Edition.

[15] Chernev, A. 2012. "Product Assortment and Consumer Choice: an Interdisciplinary Review." Foundations and Trends in Marketing 6: 1-61.

[16] vanHerpen, E., and van Trijp, H. C. M. 2011. "Front-of-pack Nutrition Labels. Their Effect on Attention and Choices when Consumers have Varying Goals and Time Constraints." Appetite 57: 148-60.

[17] Oppewal, H., and Koelemeijer, K. 2005. "More Choice is Better: Effects of Assortment Size and Composition on 
Assortment Evaluation.” International Journal of Research in Marketing 22: 45-60.

[18] Drichoutis, A. C., Lazaridis, P., and Nayga, R. M. 2006. "Consumer Use of Nutritional Food Labels - a Review of Research Studies and Issues." Academy of Marketing Science Review 9: 1-22.

[19] Mantrala, M. K., et al. 2009. "Why is Assortment Planning so Difficult for Retailers? A Framework and Research Agenda." Journal of Retailing 85: 71-83.

[20] Colby, S. E., Johnson, L., Scheett, A., and Hoverson, B. 2010. "Nutrition Marketing on Food Labels." Journal of Nutrition Education and Behavior 42: 92-8.

[21] Oip, S., Teixeira, E., and Deliza, R. 2006. "Consumer Research: Extrinsic Variables in Food Studies.” British Food Journal 108: 894-903.

[22] Hoyer, W. D., and MacInnis, D. J. 2010. "Consumer Behavior." Mason, OH: South-Western.

[23] Milosavljevic, M., Koch, C., and Rangel, A. 2011 "Consumers can Make Decisions in As Little As a Third of a Second." Judgment and Decision Making 6: 520-30.

[24] Silayoi, P., and Speece, M. 2004. "Packaging and Purchase Decisions. An Exploratory Study on the Impact of Involvement Level and Time Pressure." British Food Journal 106: 607-28.

[25] Peter, J., and Olson, J. 2010. “Consumer Behavior.” The Graw-Hill Companies.

[26] Deliza, R., and MacFie, H. 2010. "Product Packaging and Branding.” In book: Frewer, L., Risvik, E., Schifferstein, H., ed. Food, People and Society - a European Perspective of Consumers' Food Choices. Berlin-Heidelberg: Springer-Verlagp: 55-72.

[27] Marín-Guerrero, A. C., Gutiérrez-Fisac, J. L., Guellar-Castillón, P., Banegas, J. R., and Rodríguez-Artalejo, F. 2008. "Eating Behaviours and Obesity in the Adult Population of Spain." British Journal of Nutrition 100: 1142-8.

[28] Cowburn, G., and Stockley, L. 2005. "Consumer Understanding and Use of Nutrition Labeling: a Systematic Review." Public Health Nutrition 8: 21-8.

[29] Ni Mhurchu, C., and Gorton, D. 2007. "Nutrition Labels and Claims in New Zealand and Australia: a Review of Use and Understanding." Australian and New Zealand Journal of Public Health 31: 105-12.

[30] Nordic Council of Ministers 2014. "Food
Labelling-Nordic Consumers' Attitudes to Food Labelling." TemaNord 2007: 513. http://www.norden.org/pub/velfaerd/livsmedel/sk/TN200 7513.pdf (27.7.2014).

[31] Grimes, C. A., Riddell, L. J., and Nowson, C. A. 2009. "Consumer Knowledge and Attitudes to Salt Intake and Labelled Salt Information.” Appetite 53: 189-94.

[32] Feunekes, G. I. J., Gortemaker, I. A., Willems, A. A., Lion, R., and van den Kommer, M. 2008. "Front-of-pack Nutrition Labelling: Testing Effectiveness of Different Nutrition Labelling Formats Front-of-pack in Four European Countries." Appetite 50: 57-70.

[33] Lobstein, T., and Davies, S. 2008. "Review Article Defining and Labelling 'Healthy' and 'Unhealthy' Food." Public Health Nutrition 123: 331-40.

[34] Sanlier, N., and Karakus, S. S. 2000. "Evaluation of Food Purchasing Behaviour of Consumers from Supermarkets." British Food Journal 112: 140-50.

[35] Bogue, J., Coleman, T., and Sorenson, D. 2005. "Determinants of Consumers' Dietary Behaviour for Health-enhancing Foods." British Food Journal 43: 4-16.

[36] Sigman-Grant, M. J. 2008. "Food Choice: Balancing Benefits and Risks." Journal of the American Dietetic Association 108: 778-80.

[37] Maggi, A. 2012. "Communicating Nutrition at the Point of Purchase." Food Technology 11: 21-7.

[38] Berning, J. P., Chouinard, H. H., Manning, K. C., McCluskey, J. J., and Sprott, D. E. 2010. "Identifying Consumer Preferences for Nutrition Information on Grocery Store Shelf Labels." Food Policy 35: 429-36.

[39] Martin, A. 2010. Sam's Club personalizes discounts for buyers. New York Times, May 30, 2010. http://www.nytimes.com/2010/05/31/business/31loyalty.h tml?pagewanted=all (27.7.2014).

[40] Chandon, P., Huchinson, W., Bradlow, E., and Young, S. 2009. "Does In-store Marketing Work? Effects of the Number and Position of Shelf Facings on Brand Attention and Evaluation at the Point of Purchase." Journal of Marketing 73: 11.

[41] Shankar, V. J., Inman, M., Mantraka, E. K., and Rizley, R. 2011. "Innovations in Shopper Marketing: Current Insights and Future Research Issues." Journal of Retailing 87: 29-42.

[42] Neff, J. 2009. "Trouble in Store for Shopper Marketing." Advertising Age 80: 3-32. 